\title{
EXCHANGE RATE DYNAMICS: WHERE IS THE SADDLE PATH?
}

\author{
YIN-WONG CHEUNG \\ JAVIER GARDEAZABAL \\ JESÚS VÁZQUEZ
}

CESIFO WORKING PAPER NO. 1129

CATEgORY 6: MONETARy POLICY AND InTERNATIONAL FinANCE

FEBRUARY 2004
An electronic version of the paper may be downloaded - from the SSRN website:
- from the CESifo website:
www.SSRN.com
www.CESifo.de




\title{
EXCHANGE RATE DYNAMICS: WHERE IS THE SADDLE PATH?
}

\begin{abstract}
A strand of exchange rate models postulate exchange rate fluctuations are driven by saddlepath dynamics and the related overshooting behavior. Using a bivariate system, the paper illustrates the relationship of the cointegration, saddle-path, and stationarity dynamics. Monte Carlo results indicate that the Johansen tests have reasonable power to discriminate saddlepath behavior from cointegration dynamics. Using monthly data from five major industrial countries, we find that exchange rates and prices are cointegrated. The cointegration result casts doubt on the use of saddle-path dynamics and the associated overshooting behavior to elucidate exchange rate variations.
\end{abstract}

Keywords: overshooting, cointegration, Johansen test, simulation, convergence behavior.

JEL Classification: F31, C12.

\author{
Yin-Wong Cheung \\ Department of Economics SS1 \\ University of California \\ Santa Cruz, CA 95064 \\ USA \\ cheung@cats.ucsc.edu
}

\author{
Javier Gardeazabal \\ Dpto. Fundamentos del Análisis \\ Económico II, Avda. \\ Lehendakari Aguirre 83 \\ 48015 Bilbao \\ Spain \\ jepgamaj@bs.ehu.es
}

Jesús Vázquez

Dpto. Fundamentos del Análisis

Económico II, Avda.

Lehendakari Aguirre 83

48015 Bilbao

Spain

jepvapej@bs.ehu.es 


\section{Introduction}

Undeniably, exchange rate behavior is one of the most intensely studied topics in the international finance literature. The overshooting model $\grave{a}$ la Dornbusch provides a prominent explanation for high variability of (real) exchange rates. Since its publication in the 1970s (Dornbusch, 1976), the overshooting model occupies a key position in modeling exchange rate dynamics (Frankel and Rose, 1995). A notable feature of the model is the saddle-path dynamics, which follows from the assumption that the price of goods and the exchange rate have different adjustment speeds. Under the sticky price assumption, the exchange rate overshoots its new equilibrium level in response to shocks so that the system reaches a new saddle-path trajectory and converges to the new equilibrium position. Strictly speaking, "overshooting dynamics" is the consequence of the presence of "saddle-path dynamics." ${ }^{1}$ In the literature, nonetheless, "overshooting" is commonly used to describe this class of exchange rate models. Thus, for convenience, in the following sections the terms "overshooting dynamics" and "saddle-path dynamics" are used interchangeably.

Several approaches have been adopted to test the overshooting model. For instance, some empirical studies are based on the reduced form exchange rate equation derived from the model. Despite the initial success of the model to describe observed data, the subsequent evidence is far from supportive (Frankel, 1979; Driskill, 1981; Driskill and Sheffrin, 1981). Other studies examine the relationship between real interest rate differentials and real exchange rates. Again, the empirical evidence is usually not in favor of the model (Meese and Rogoff, 1988; Edison and Pauls, 1993).

Engel and Morley (2001) consider a modified overshooting model that does not require exchange rates and prices to have the same adjustment speed. 
2

Using an unobserved component specification, the authors find prices adjust faster toward their equilibrium values - a result that lends support to the modified overshooting model. Cheung, Lai and Bergman (2004), on the other hand, compare the individual contributions of exchange rate and price movements to real exchange rate dynamics. It is found that real exchange rate dynamics are mainly driven by exchange rate adjustments while the reversion to real exchange rate equilibrium is attributable to price adjustments. Also, exchange rate movements tend to amplify and prolong deviations from the equilibrium real exchange rate. The finding is at odds with the adjustment mechanism predicted by the standard overshooting model.

Several studies directly evaluate the effect of monetary shocks on exchange rates and, hence, infer the validity of the overshooting hypothesis. Eichenbaum and Evans (1995), for instance, find that exchange rate overshooting exists but the maximal impact of a monetary shock on exchange rates occurs with a lag of two to three years. The finding is not entirely consistent with the overshooting model à la Dornbusch, which predicts exchange rate overshooting is instantaneously triggered by the shock. The non-instantaneous overshooting phenomenon appears to be a common empirical regularity (Cheung and Lai, 2000; Clarida and Gali, 1994). Faust and Rogers (1999), however, argue that the observed non-instantaneous overshooting effect derived from a vector autoregression (VAR) system can be spurious. These authors point out that the timing of the maximum monetary shock effect depends on the assumptions used to identify the VAR system. They show that the identification scheme proposed by Faust (1998) can be used to obtain the almost immediate overshooting effect.

This study offers an alternative perspective to evaluate the validity of the overshooting hypothesis. Essentially, we exploit the implication of the saddle- 
path mechanism, which is the driving force of the overshooting result, for data dynamics. The intertemporal dynamics of a given system are governed by the roots of its characteristic polynomial. In the exchange rate literature, the saddlepath property that yields the overshooting phenomenon is defined by the presence of both explosive and stationary roots. Typically, some transversality conditions are imposed to limit the effects of explosive roots so that the system can settle on the saddle path that leads to the steady state.

To certain extent, the characterization of saddle-path dynamics is comparable to, but different from, that of cointegration. Both saddle-path and cointegration dynamics depend upon the roots of the system's characteristic polynomial. Such a similarity suggests that a test for cointegration may be adopted to test for the presence of saddle-path dynamics.

This paper explores whether the Johansen procedure, a standard approach to test for cointegration, is a useful tool to detect saddle-path dynamics. Instead of testing for non-stationary behavior directly, the Johansen test exploits the implications of cointegration for the rank of the coefficient matrix defined by the characteristic polynomial and uses the rank condition to infer system dynamics. By using rank conditions, the Johansen test sidesteps some technical issues of hypothesis testing in the presence of non-stationarity. Indeed, it can be shown that the saddle-path and cointegration dynamics have different implications for the rank of the coefficient matrix defined by the characteristic polynomial. Specifically, the presence of cointegration is not consistent with saddle-path dynamics. Thus, the Johansen procedure can be used to discriminate between the two types of system dynamics.

When we apply the Johansen procedure to study the interaction between exchange rates and relative prices, we find that exchange rates and relative prices 
4

are cointegrated. The empirical results are suggestive of the absence of the Dornbusch-type overshooting behavior in the data.

A canonical Dornbusch-type overshooting is presented in the next section. Section 3 describes the design of the Monte Carlo experiment and reports the empirical power of the Johansen procedure for detecting saddle-path dynamics. The results of testing for cointegration in monthly data from five industrial countries are presented in Section 4. Section 5 offers some concluding remarks.

\section{An Overshooting Model}

For illustrative purposes, we present a standard overshooting model à la Dornbusch. The sticky-price assumption is a key element of the standard Dornbusch model. Although the purchasing power parity is assumed to hold in the long run, prices are assumed to be inflexible in the short run and do not react instantaneously to a shock. The overshooting phenomenon occurs because, in respond to a monetary shock, the exchange rate has to adjust to clear not just the foreign exchange market but also the goods market to attain a short-run equilibrium. The gradual price adjustment is the mechanism bringing the system to the long-run equilibrium.

A stochastic version of Dornbusch's overshooting model can be formulated as follows (Azariadis, 1993, chapter 5):

$$
\begin{aligned}
& i_{t}-i_{t}^{*}=E_{t} e_{t+1}-e_{t} \\
& m_{t}-p_{t}=\phi y_{t}-\eta i_{t}+u_{t} \\
& y_{t}=\delta\left(e_{t}+p_{t}^{*}-p_{t}\right)-\sigma\left(i_{t}-E_{t}\left(p_{t+1}-p_{t}\right)\right)+\varepsilon_{t} \\
& E_{t} p_{t+1}-p_{t}=\alpha\left(y_{t}-\bar{y}\right)
\end{aligned}
$$


where all variables (except the interest rates) are in logarithms and all parameters are non-negative. Equation (1) captures the uncovered interest rate parity condition: with $e_{t}$ being the nominal exchange rate defined as the domestic price of foreign currency and $i_{t}\left(i_{t}^{*}\right)$ being the domestic (foreign) interest rate. The domestic nominal interest rate can exceed the foreign rate when the market anticipates a depreciation of the domestic currency. Equation (2) describes a money-market equilibrium relationship, where $m_{t}$ is the nominal money supply, $p_{t}$ is the price level and $y_{t}$ is the real national income. The shock to the monetary equilibrium is given by $u_{t}$. Equation (3) states that the income level is demand determined. A real depreciation raises demand and so does a fall in the real interest rate. $\varepsilon_{t}$ is a real demand shock. Equation (4) governs the price adjustment scheme. Although prices are predetermined and do not respond instantly to current realizations of other variables, they adjust gradually over time in response to the excess of aggregate demand over the natural/full employment output level $(\bar{y})$

Conceptually, the model generates overshooting behavior in the following manner. With short-run price stickiness, an unanticipated monetary expansion induces a fall in domestic interest rates and leads to a capital outflow that will lead to the overshooting of the domestic currency to the point where the expected rate of appreciation exactly offsets the interest differential. Moreover, aggregate demand is boosted by the currency depreciation and lower interest rates. In response to higher aggregate demand, prices begin to rise slowly, thereby reducing the real money supply and pushing domestic interest rates back up. The domestic currency then appreciates gradually over time, along with rising prices. The gradual price adjustment will drive both the exchange rate and the real 
6

exchange rate to converge asymptotically to their corresponding equilibrium levels.

The implications of the equations (1) to (4) for exchange rate dynamics can be seen from the solution of the model. Following the standard procedure, we assume the foreign interest rate, the foreign price, and the domestic money supply are constant; that is, $i_{t}^{*}=i^{*}, p_{t}^{*}=p^{*}, m_{t}=m$. The resulting solutions of the exchange rate and price paths are given by a system of first-order simultaneous difference equations:

$$
\begin{aligned}
e_{t+1}-e_{t}= & (1 / \eta)\left(p_{t}-\bar{p}\right)+v_{1 t+1} \\
p_{t+1}-p_{t}= & (\alpha \delta /(1-\alpha \sigma))\left(e_{t}-\bar{e}\right) \\
& -(\alpha(\delta+(\sigma / \eta)) /(1-\alpha \sigma))\left(p_{t}-\bar{p}\right)+v_{2 t+1}
\end{aligned}
$$

where $\bar{e}$ and $\bar{p}$ are the respective steady-state values of the exchange rate and the price level. The zero mean disturbance terms $v_{1 t+1}$ and $v_{2 t+1}$ are combinations of monetary shocks, real shocks and prediction errors. The system can be compactly written as

$$
\Delta X_{t+1}=\mu+A X_{t}+V_{t+1}
$$

where $X_{t+1}=\left(e_{t+1}, p_{t+1}\right)^{\prime}, \Delta=(1-L), L$ is the lag operator, the constant $\mu$ is a function of the parameters and the steady-state values of the exchange rate and price, and

$$
A=\left(\begin{array}{cc}
0 & \frac{1}{\eta} \\
\frac{\alpha \delta}{1-\alpha \sigma} & -\frac{\alpha(\delta+(\sigma / \eta))}{1-\alpha \sigma}
\end{array}\right) .
$$

Let $\theta_{1}<\theta_{2}$ be the two roots of the characteristic equation $|A-\theta I|=0 .^{2}$ Depending on parameter configuration, the model can generate different types of dynamics. 
For instance, under the assumption that $\alpha \sigma<1$, then the determinant of $A$, $|A|=\theta_{1} \theta_{2}=-(\alpha \delta /(1-\alpha \sigma) \eta)<0$, the two roots have different algebraic signs, implying that $\theta_{1}<0<\theta_{2}$. Therefore, $\theta_{2}$ is the explosive root and $\theta_{1}$ is the stationary root. In this case, the system exhibits saddle-path dynamics and the associated overshooting behavior.

The popular cointegration dynamics are also encompassed under (7). Note that equation (7) is already in an error correction format. For cointegration to take place, the rank of matrix $A$ should be equal to one and $|A|=0$. For instance, the rank condition is satisfied when $\delta=0$; that is, aggregate demand does not respond to the real exchange rate. When $\delta=0$, the roots are $\theta_{1}=-(\alpha \sigma /(1-\alpha \sigma) \eta)<0$ and $\theta_{2}=0$. Therefore, cointegration dynamics can be viewed as a limiting case of saddle-path behavior, in particular, when $\delta$ tends to zero.

Figures 1 and 2 illustrate the saddle-path and cointegration dynamics respectively. Technically speaking, the saddle-path dynamics are described by the unique manifold that leads the system towards its steady state. Appropriate initial conditions place the economy on the saddle-path manifold. Figure 1 gives a canonical phase diagram for a saddle-path system. The arrows indicate the system dynamics. The unique trajectory that brings the system to its steady state is the saddle-path line, denoted by the SP line in Figure 1.

For a cointegrated system, only one common I(1) process drives the evolution of the system components. The system converges to its steady state disregarding the initial conditions. Under cointegration, there are an infinite number of trajectories that bring the system to its equilibrium. Notice that the slope of the phase line $\Delta p_{t}=0$ is equal to $\alpha \delta /(\alpha(\delta+(\sigma / \eta)))$. Therefore as $\delta$ tends to zero, the phase line $\Delta p_{t}=0$ rotates clock-wise until it overlaps with the $\Delta e_{t}=0$ 
8

phase line. Figure 2 depicts the phase diagram of a cointegrated system, where the two lines overlap. When $\delta$ tends to zero, the explosive region in Figure 1 disappears and there is an infinite number of paths leading to the line where the two phase lines overlap. The manifold where the two phase lines overlap is known as the "attractor" of the system.

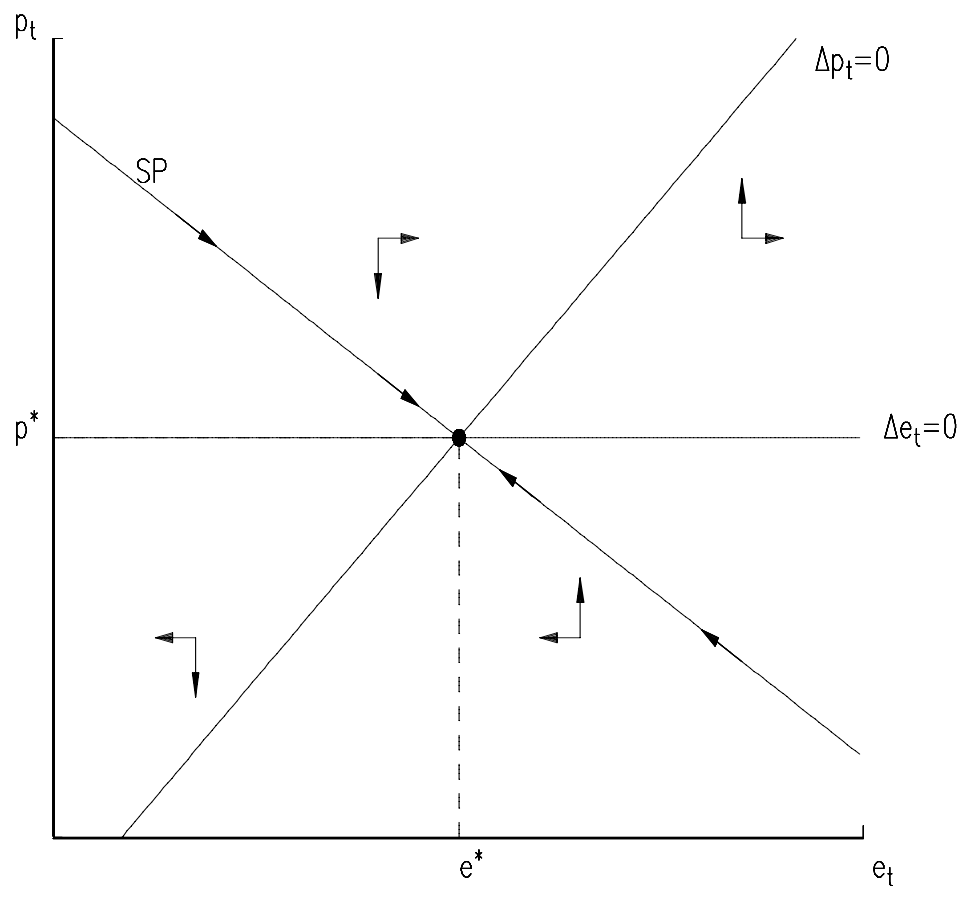

Figure 9.1 Saddle Path Dynamics 


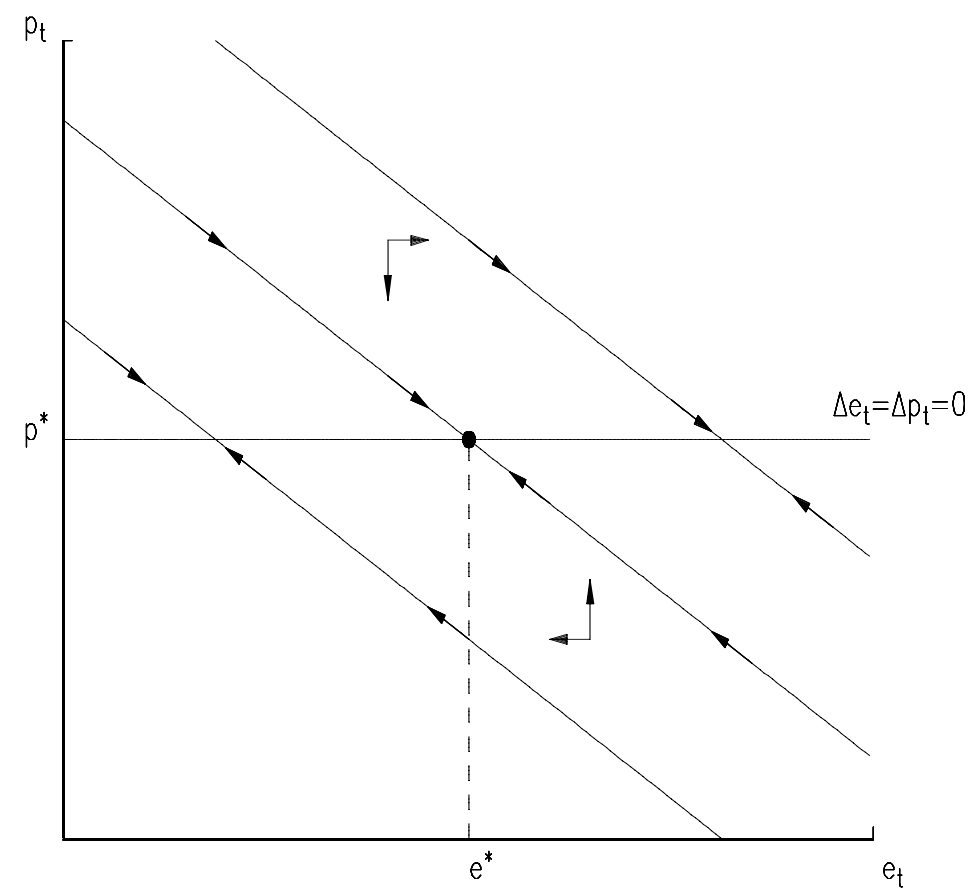

Figure 2 Cointegration Dynamics

There is another case that deserves attention. When $\alpha=0$, the price level follows a random walk (a martingale difference process, to be precise), the rank of matrix $\mathrm{A}$ is null, and there is no cointegration between prices and exchange rates. Apparently, this case is not relevant to empirical data on exchange rates and prices examined in Section 4 because these data are typically non-stationary and prices do not follow a martingale.

\section{Detecting Saddle-path Behavior}

The discussion in the previous section suggests that the rank of $A$ can be used to infer the dynamics of the system. Instead of deriving a new testing 
10

method, we observe that the Johansen's procedure, which is a standard test for cointegration, uses the rank of $A$ to infer the system dynamics. Thus, we explore the possibility of using the Johansen's procedure to discriminate the saddle-path and stationary systems from a cointegrated system.

For a bivariate difference-stationary system, the Johansen procedure is usually implemented as follows. First, the maximum eigenvalue statistic of the Johansen procedure tests the null hypothesis $H_{0}: \operatorname{rank}(A)=0$ against the alternative $H_{1}: \operatorname{rank}(A)=1$. Under $H_{0}$, the unit root components of two individual series are driven by two different $I(1)$ processes and there is no cointegration. Under $H_{1}$, the variables are cointegrated and the two variables are driven by one common $I(1)$ process and one stationary process. If $H_{0}$ is rejected, the procedure then considers the hypothesis $H_{1}: \operatorname{rank}(A)=1$ against the alternative $H_{2}: \operatorname{rank}(A)=2$. While the cointegration dynamics is consistent with the nonrejection of $H_{1}$, either a stationary system or a saddle-path system implies $A$ has full rank. It is interesting to recall that, in the previous section, it is shown that a cointegration system can be interpreted as a limiting case of either a saddle-path system or a stationary system.

In the literature, there are several studies examining the empirical performance of the Johansen procedure (Cheung and Lai, 1993b; Gonzalo 1994). Typically these studies consider the cointegration rather than the saddle-path alternative. The Johansen procedure is constructed to test for the rank of $A$ and, at least theoretically, can be used to detect saddle-path behavior. The natural question to ask is - "What is the empirical power of the Johansen's tests against the saddle-path alternative?" A Monte Carlo experiment is designed to shed some 
insights on the power issue. Again, a bivariate system that has the form of (7) is used to illustrate the point.

TABLE 1. The Empirical Power of the Johansen Maximum Eigenvalue Statistic Against Saddle-Path Alternatives

\begin{tabular}{lllllll}
\hline Roots & & $\mathrm{T}=100$ & \multicolumn{3}{l}{$\mathrm{T}=300$} \\
\hline$\theta_{2}$ & $\theta_{1}$ & $H_{0} v s H_{1}$ & $H_{1} v s H_{2}$ & $H_{0} v s H_{1}$ & $H_{1} v s H_{2}$ \\
\hline 0.20 & -0.20 & 1.0 & 0.7845 & 1.0 & 1.0 \\
$\sigma_{0}=0.20$ & -0.10 & 1.0 & 0.5119 & 1.0 & 0.9944 \\
& 0.20 & -0.01 & 1.0 & 0.1027 & 1.0 & 0.2023 \\
& 0.10 & -0.20 & 1.0 & 0.5186 & 1.0 & 0.9936 \\
& 0.10 & -0.10 & 1.0 & 0.3703 & 1.0 & 0.9508 \\
& 0.10 & -0.01 & 1.0 & 0.1087 & 1.0 & 0.1977 \\
& 0.01 & -0.20 & 1.0 & 0.1120 & 1.0 & 0.2004 \\
& 0.01 & -0.10 & 1.0 & 0.1244 & 1.0 & 0.1938 \\
& 0.01 & -0.01 & 1.0 & 0.1686 & 1.0 & 0.1566 \\
\hline & 0.20 & -0.20 & 0.9995 & 0.8355 & 1.0 & 1.0 \\
& 0.20 & -0.10 & 0.9715 & 0.5779 & 1.0 & 0.9980 \\
& 0.20 & -0.01 & 0.9283 & 0.1114 & 1.0 & 0.1956 \\
$\sigma_{0}=0.10$ & -0.20 & 0.9981 & 0.5565 & 1.0 & 0.9974 \\
& 0.10 & -0.10 & 0.8976 & 0.4221 & 1.0 & 0.9640 \\
& 0.10 & -0.01 & 0.7304 & 0.1391 & 1.0 & 0.1867 \\
& 0.01 & -0.20 & 0.9943 & 0.1148 & 1.0 & 0.2052 \\
& 0.01 & -0.10 & 0.7893 & 0.1313 & 1.0 & 0.2028 \\
0.01 & -0.01 & 0.4326 & 0.1301 & 0.7625 & 0.1688 \\
\hline$\sigma_{0}=1.0$ & 0.10 & -0.10 & 0.3279 & 0.5974 & 1.0 & 0.9939 \\
0.10 & -0.01 & 0.2619 & 0.0672 & 0.9487 & 0.0544 \\
& 0.01 & -0.20 & 0.8304 & 0.1163 & 1.0 & 0.2014 \\
0.01 & -0.10 & 0.2393 & 0.2173 & 1.0 & 0.1997 \\
0.01 & -0.01 & 0.2429 & 0.0543 & 0.2119 & 0.1369 \\
\hline 0.20 & -0.20 & 0.8881 & 0.9573 & 1.0 & 1.0 \\
0.20 & -0.10 & 0.5943 & 0.8082 & 1.0 & 0.9995 \\
& 0.10 & -0.20 & 0.8253 & 0.7037 & 1.0 & 0.0521 \\
\hline & & & & & &
\end{tabular}


TABLE 1 Continued.

\begin{tabular}{cllllll}
\hline Roots & \multicolumn{3}{c}{$\mathrm{T}=100$} & \multicolumn{3}{c}{$\mathrm{T}=300$} \\
\hline$\theta_{2}$ & $\theta_{1}$ & $H_{0} v s H_{1}$ & $H_{1} v s H_{2}$ & $H_{0} v s H_{1}$ & $H_{1} v s H_{2}$ \\
\hline 0.20 & -0.20 & 0.7946 & 0.9911 & 1.0 & 1.0 \\
0.20 & -0.10 & 0.4929 & 0.9503 & 1.0 & 1.0 \\
0.20 & -0.01 & 0.4770 & 0.0027 & 1.0 & 0.0057 \\
$\sigma_{0}=10.0$ & 0.10 & -0.20 & 0.7024 & 0.7809 & 1.0 & 1.0 \\
& 0.10 & -0.10 & 0.2123 & 0.7612 & 1.0 & 0.9999 \\
& 0.10 & -0.01 & 0.1951 & 0.0046 & 0.9017 & 0.0065 \\
& 0.01 & -0.20 & 0.7479 & 0.1223 & 1.0 & 0.2087 \\
0.01 & -0.10 & 0.1465 & 0.2874 & 1.0 & 0.2077 \\
0.01 & -0.01 & 0.2180 & 0.0234 & 0.1244 & 0.0748 \\
\hline
\end{tabular}

Note to Table 1: The empirical rejection frequencies of applying the Johansen maximum eigenvalue test to artificial data generated according to saddle-path dynamics are reported. The rejection frequencies are based on 10,000 replications and a 5\% critical value. Two sample sizes; $\mathrm{T}=100$ and $\mathrm{T}=300$, are considered. The hypotheses are defined by $\mathrm{H}_{0}: \operatorname{rank}(\mathrm{A})=0, \mathrm{H}_{1}: \operatorname{rank}(\mathrm{A})$ $=1$, and $\mathrm{H}_{2}: \operatorname{rank}(\mathrm{A})=2$. Two rejection frequencies are recorded. The first one reported under the column " $H_{0} v s H_{1}$ " is the frequency of $\mathrm{H}_{0}$ being rejected. The second one reported under " $H_{0} v s H_{1}$ " is the frequency of $\mathrm{H}_{1}$ being rejected conditioning on the rejection of $\mathrm{H}_{0}$. The characteristic roots of the system are given by $\theta_{1}$ and $\theta_{2}$. The standard deviation of the initial condition is given by $\sigma_{0}$. See the text for a more detailed description of the simulation.

The Monte Carlo experiment is conducted as follows. First, $T$ observations of $X_{t}$ are generated according to saddle-path dynamics. The Appendix contains information on the procedure used to generate the data. Second, the maximum eigenvalue statistic is used to test the hypothesis $H_{0}: \operatorname{rank}(A)=0$ against the alternative $H_{1}: \operatorname{rank}(A)=1$. If $H_{0}$ is rejected in favor of $H_{1}$, then $H_{1}$ is tested against the alternative $H_{2}: \operatorname{rank}(A)=2$. Third, the procedure is repeated $N$ times. Two rejection frequencies are recorded. The first one is the frequency of $H_{0}$ being rejected. The second one is the frequency of $H_{1}$ being rejected, conditioning on the rejection of $H_{0}$. The following parameter values are 
considered: $T=(100,300), N=10,000, \theta_{1}=(-0.20,-0.1,-0.01), \theta_{2}=(0.20$, $0.1,0.01)$, and $\sigma_{i}^{2}=\operatorname{var}\left(v_{i t}\right)=0.01$. An additional parameter is the variance of the distribution $\left(\sigma_{0}^{2}\right)$ from which the initial observation is drawn. The values of $\sigma_{0}$ used in the experiment are $0,0.1,1$, and 10 .

Because the Johansen's methodology is a standard test procedure, we refer the reader to, for example, Johansen and Juselius (1990), for a detailed discussion of the procedure and of the construction of the maximum eigenvalue statistic.

The simulations results are reported in Table 1. The rejection frequencies are derived using the $5 \%$ critical value. One relatively easy to interpret result is that the power increases with the sample size. Conditional on the other parameter values, the rejection frequency increases with the sample size - that is, the test is consistent. The implications of the roots $\theta_{1}$ and $\theta_{2}$ for the rejection frequencies are quite intuitive. In general, the further away the roots are from zero, the higher is the rejection frequency. Exceptions occur when $T=100, \theta_{1}=-0.01$ and $\theta_{2}=$ 0.01. In some of these cases, the rejection frequency for $H_{1}$ against $H_{2}$ is higher than in some other parameter combinations in which the roots are further away from zero. However, the apparent odd result disappears when the rejection frequency for $H_{1}$ against $H_{2}$ is computed without conditioning on the rejection of $H_{0}$.

It is interesting to observe that, for the two tests $H_{0}$ against $H_{1}$ and $H_{1}$ against $H_{2}$, both $\theta_{1}$ and $\theta_{2}$ have comparable effects on the rejection frequencies. The observation is consistent with the fact that the Johansen procedure is a test for the rank of the relevant coefficient matrix. When either $\theta_{1}$ or $\theta_{2}$ is approaching zero, the rank of the relevant matrix is approaching one, the system dynamics are 
14

shifting towards $H_{1}$, and it is getting more and more difficult to reject $H_{1}$. As a general rule, when both $\theta_{1}$ and $\theta_{2}$ are close to zero, the rank is close to zero and the test has low power to reject $H_{0}$. It is not too surprising to observe the limited power of the test, especially when $\theta_{1}=-0.01$ and $\theta_{2}=0.01$. Statistical tests always have low power for alternatives that are very close to the null hypothesis.

The effect of $\sigma_{0}$ appears intricate. When $\sigma_{0}=0$, all simulated time series are initially at the steady state. The system moves away from the steady state in the presence of random shocks and, then, follows the saddle-path to the new steady state. When $\sigma_{0}>0$, the initial position of the system is not necessarily at the steady state. The greater $\sigma_{0}$, the more likely the system is initially far away from the steady state. In fact, the $\sigma_{0}$ parameter can have two opposite effects on the empirical power. On the one hand, when $\sigma_{0}$ is large, the initial shock moves the system far away from the steady state and, hence, the system stays for a long time on the converging saddle path. Intuitively, it would be easier for the test to reveal the saddle-path dynamics. On the other hand, a large $\sigma_{0}$ introduces a high level of noise and, subsequently, makes it more difficult to reject the nonstationarity (null) hypothesis and less easy to uncover saddle-path dynamics.

The results in Table 1 indicate that the effect of $\sigma_{0}$ depends on the roots $\theta_{1}$ and $\theta_{2}$. It is instructive to compare the two extremes cases $\left(\theta_{1}=-0.20\right.$ and $\theta_{2}=$ $0.20)$ and $\left(\theta_{1}=-0.01\right.$ and $\left.\theta_{2}=0.01\right)$. In the former case, the roots are quite different from zero and the system is far away from $H_{0}$ and $H_{1}$. An increase in the value of $\sigma_{0}$ from 0 to 1 is accompanied with an increase in the number of cases in which favorable evidence is gardened for $\mathrm{H}_{2}$. The result holds when either the conditional rejection frequency (the one reported in the table) or the total rejection 
frequency is considered. Thus, for this parameter configuration, an increase in the value of $\sigma_{0}$ from 0 to 1 improves the ability to detect saddle-path dynamics. The rejection frequency falls, however, when $\sigma_{0}$ is increased from 1 to 10 . Thus, when the noise level associated with $\sigma_{0}$ is high (relative to the distance from $H_{0}$ and $\left.H_{1}\right), \quad \sigma_{0}$ negatively affects the power of the test to detect saddle-path dynamics. For the case $\theta_{1}=-0.01$ and $\theta_{2}=0.01$, the system is very close to having two zero roots. Under this situation, an increase in the value of $\sigma_{0}$ makes it more difficult to discern the saddle-path dynamics and, thus, lowers the ability of the test to reject $H_{0}$ and $H_{1}$. The positive (negative) effect of $\sigma_{0}$ on ability to reveal saddle-path dynamics dominates when the system dynamics is far away from (close to) those implied by $H_{0}$ and $H_{1}$.

TABLE 2. The Empirical Power of the Johansen Maximum Eigenvalue Statistic Against Stationary Alternatives

\begin{tabular}{llllll}
\hline Roots & \multicolumn{3}{c}{$\mathrm{T}=100$} & \multicolumn{3}{c}{$\mathrm{T}=300$} \\
\hline$\theta_{2}$ & $\theta_{1}$ & $\begin{array}{l}\text { Ho Vs } \\
\text { H1 }\end{array}$ & H1 Vs H2 & Ho Vs & H1 Vs H2 \\
& & 1.0 & 0.8349 & 1.0 & 1.0 \\
\hline-0.20 & -0.20 & 1.0 & 0.5641 & 1.0 & 0.9974 \\
-0.20 & -0.10 & 1.0 & 0.1042 & 1.0 & 0.1972 \\
-0.20 & -0.01 & 1.0 & 0.5485 & 1.0 & 0.9975 \\
-0.10 & -0.20 & 1.0 & 0.3980 & 1.0 & 0.9613 \\
-0.10 & -0.10 & 1.0 & 0.1135 & 1.0 & 0.1862 \\
-0.10 & -0.01 & 1.0 & 0.1064 & 1.0 & 0.2028 \\
-0.01 & -0.20 & 1.0 & 0.1128 & 1.0 & 0.1939 \\
-0.01 & -0.10 & 1.0 & 0.1326 & 1.0 & 0.1551 \\
-0.01 & -0.01 & & & & \\
\hline
\end{tabular}

Notes to Table 2: The empirical rejection frequencies of applying the Johansen maximum eigenvalue test to artificial data generated according to stationary dynamics are reported. The rejection frequencies are based on 10,000 replications and a 5\% critical value. Two sample sizes; 
16

$\mathrm{T}=100$ and $\mathrm{T}=300$, are considered. The hypotheses are defined by $\mathrm{H}_{0}: \operatorname{rank}(\mathrm{A})=0, \mathrm{H}_{1}$ : $\operatorname{rank}(\mathrm{A})=1$, and $\mathrm{H}_{2}: \operatorname{rank}(\mathrm{A})=2$. Two rejection frequencies are recorded. The first one reported under the column " $\mathrm{H}_{0} v s H_{1}$ " is the frequency of $\mathrm{H}_{0}$ being rejected. The second one reported under " $\mathrm{H}_{1} v s \mathrm{H}_{2}$ " is the frequency of $\mathrm{H}_{1}$ being rejected conditioning on the rejection of $\mathrm{H}_{0}$. The characteristic roots of the system are given by $\theta_{1}$ and $\theta_{2}$. See the text for a more detailed description of the simulation.

In conducting the simulation experiment, the Johansen trace statistics were also computed. However, the empirical power estimates based on the trace statistic are very similar to those based on the maximum eigenvalue statistic. Different values of $\sigma_{1}^{2}$ and $\sigma_{2}^{2}$ were also included in the experiment. It turns out that the simulation results are quite insensitive to a) the value of $\sigma_{1}^{2}$ and $\sigma_{2}^{2}$, and b) the relative size of of $\sigma_{1}^{2}$ and $\sigma_{2}^{2}$. Thus, the simulation results related to the trace statistic and different combinations of $\sigma_{1}^{2}$ and $\sigma_{2}^{2}$ are not reported for brevity. These results are available from the authors upon request.

While the results indicate that the Johansen procedure has a reasonable power to uncover saddle-path behavior, it is noted that a stationary bivariate system can lead to similar rejection results. It is instructive to assess the power of the test in the presence of stationary data. To this end, we apply the Johansen procedure to data generated under stationary alternatives. The stationary roots considered are $\theta_{1}, \theta_{2}=(-0.2,-0.10,-0.01)$. The other parameters are the same as those considered in Table 1. Table 2 reports the power of the Johansen procedure against the stationary alternatives when we set $\sigma_{0}=0$.

Similar to the saddle-path experiment, the empirical power in Table 2 is increasing with the sample size and the distance of the roots from zero. Compared with results in Table 1, results in Table 2 indicate that the Johansen maximum 
eigenvalue statistic has reasonable power in detecting the full rank condition no matter it is generated by saddle-path or stationary dynamics.

\section{Exchange Rate Dynamics}

In this section, we use the Johansen procedure to infer whether the saddlepath and the related overshooting dynamics are an appropriate description of exchange rate dynamics. Four dollar-based exchange rates namely British pound, French franc, German mark, and Italian lira are included in the sample. Monthly data of nominal exchange rates and consumer price indexes from April 1973 to December 1998 were retrieved from the International Financial Statistics data CD-ROM. These data are expressed in logarithms. As commonly conceived, the individual exchange rate and price series display I(1) non-stationarity. Following the literature, the bivariate system comprising of the nominal exchange rate and the relative price is employed to study the cointegration relationship between exchange rates and relative prices.

For notational purposes, a bivariate system as (7) is re-writen in its general form:

$$
\Delta X_{t}=\mu+A X_{t-1}+\sum_{i=1}^{k-1} A_{i} X_{t-i}+V_{t}
$$

where no parameter restriction is imposed on matrices $A$ and $A_{i}$. The lagged $X_{t}$ 's are included to ensure that $V_{t}$ follows a white noise process and that the Johansen result is not distorted by serial correlation in the error term. In implementing the test, the lag parameter $\mathrm{k}$ is selected using the Akaike information criterion. Both the Johansen maximum eigenvalue and trace statistics are calculated. Again we refer readers to Johansen and Juselius (1990) for the construction of these test statistics. 


\section{TABLE 3. Johansen cointegration test results}

\begin{tabular}{|c|c|c|c|c|c|}
\hline & Max. Eige & nvalue Stat. & Trace Sta & & \\
\hline & $\operatorname{Rank}(\mathrm{A})$ & $=\operatorname{Rank}(\mathrm{A})$ & $=\operatorname{Rank}(\mathrm{A})$ & $=\operatorname{Rank}(\mathrm{A})$ & $=$ \\
\hline & 0 & 1 & 0 & 1 & \\
\hline British Poul & & & & & \\
\hline Lag $=2$ & $21.3878^{*}$ & 5.3478 & $26.7356^{*}$ & 5.3478 & \\
\hline French Frar & & & & & \\
\hline $\mathrm{Lag}=4$ & $34.7165^{*}$ & 4.3357 & $39.0522 *$ & 4.3357 & \\
\hline German Ma & & & & & \\
\hline $\mathrm{Lag}=1$ & $15.9658 * *$ & 3.9937 & $19.9595^{*}$ & 3.9937 & \\
\hline Italian Lira & & & & & \\
\hline Lag = 1 & $26.6205 *$ & 4.9276 & $31.5481 *$ & 4.9276 & \\
\hline
\end{tabular}

Notes to Table 3: The Johansen tests for cointegration between nominal exchange rates and relative prices are presented. Both the maximum eigenvalue statistic "Max. Eigenvalue Stat." and the trace statistics "Trace Stat." are reported. The null hypotheses are given underneth the statistic labels. The alternatives for the maximum eigenvalue statistic are $\operatorname{Rank}(\mathrm{A})=1$ and $\operatorname{Rank}(\mathrm{A})=2$ and the those for the trace statistic $\operatorname{are} \operatorname{Rank}(\mathrm{A})>0$ and $\operatorname{Rank}(\mathrm{A})>1$. The lag paramter $" \mathrm{Lag}="$ is selected using the Akaike information criterion. Significance at the 5\% and $1 \%$ levels are indicated by "**" and "** according to the finite sample critical values in Cheung and Lai (1993b). The hypothesis of $\operatorname{Rank}(\mathrm{A})=0$ is rejected by both statistics but the hypothesis of $\operatorname{Rank}(\mathrm{A})=1$ is not rejected.

The results of the Johansen tests are reported in Table 3. Both the maximum eigenvalue and trace statistics reject the null hypothesis $H_{0}: \operatorname{rank}(A)=0$ but not the null hypothesis $H_{1}: \operatorname{rank}(A)=1$. Thus, the exchange rate and the relative price are cointegrated and the two series in each bivariate system are driven by a common I(1) process. Individually, each series evolves as a nonstationary I(1) process. However, a unique combination of the two series governed by the cointegrating vector is stationary. Typically, the cointegration 
result is interpreted as the evidence of the presence of an empirical long-run relationship between exchange rates and prices, which constitutes a necessary condition for long-run purchasing power parity (Cheung and Lai, 1993a; Kugler and Lenz, 1993).

The results in the previous sections allow us to use the rank of $A$ to infer the system dynamics from a different perspective. In addition to the long-run relationship interpretation, our results also indicate that neither the notion of saddle-path nor stationary dynamics are consistent with the inference that the rank of $\mathrm{A}$ is equal to one. Because exchange rates and relative prices are $\mathrm{I}(1)$ processes, the bivariate system consisting of these two variables is not stationary. Thus, the strength of the result is its implications for the irrelevance of using saddle-path and the related overshooting dynamics to describe exchange rate behavior.

There are a few caveats in generalizing the cointegration results. First, the empirical illustration includes only a few countries even though these are the key industrial countries. It is fair to say that a more definite inference on the relevancy of saddle-path dynamics still awaits additional results from a larger set of dollarbased exchange rates and cross-rates. Second, as indicated in the simulation experiment, the ability to detect saddle-path dynamics is severely handicapped when the explosive root is very close to one. Further analyses are required to rule out this possibility. Nonetheless, the cointegration results in Table 3 cast doubt on the general validity of saddle-path/overshooting exchange rate dynamics.

\section{Concluding Remarks}

The overshooting model à la Dornbusch is a prominent explanation for the volatile exchange rate behavior in the current floating period. Assuming prices are 
sticky, the model displays a saddle-path pattern and yields overshooting dynamics that induces high short-term exchange rate volatility. Using a bivariate system, this study illustrates the implications of saddle-path, cointegration, and stationary dynamics for the characteristic roots that determines the system's intertemporal behavior. It is shown that a cointegration system can be interpreted as a limiting case of a system that displays either saddle-path or stationarity dynamics. A Monte Carlo experiment is designed to illustrate the usefulness of the Johansen tests to uncover saddle-path dynamics. The simulation results indicate that the Johansen tests have a) reasonable power to detect saddle-path dynamics, and b) similar power to reject the cointegration hypothesis in favor of saddle-path or stationarity alternatives.

Our empirical example shows that exchange rates and prices are cointegrated. Because the variables in a saddle-path system are not supposed to display a cointegrating relationship, the empirical evidence is indicative of the absence of saddle-path dynamics in the data under investigation. Exchange rate models that do not rely on saddle-path properties and over-shooting dynamics may deserve some more serious attention.

It is conceivable that the implications of the current study go beyond the exchange rate saddle-path behavior. There are models in different areas in economics exhibiting saddle-path properties. For instance, the neo-classical growth model (Cass, 1965) is an early example in which saddle-path dynamics are used to elaborate balanced-growth. Other models that utilize saddle-path dynamics to elucidate relationships between economic variables include those of Bruno and Fischer (1991) for interest rates and inflation, Evans and Yarrow (1981) for real money balances and inflation. The saddle-path property in these models, however, is not commonly subject to direct empirical test. 
Nonetheless, it is noted that some studies report cointegrating relationship between a) output, investment, and consumption (King et al., 1991) ${ }^{3}$ and between interest rates and inflation (Bonham; 1991). These cointegration results imply the saddle-path models may not be appropriate for these variables.

While the Johansen procedure, as illustrated in previous sections, can be used to test for saddle-path dynamics, further studies on other testing procedures for saddle-path dynamics are warranted; especially given the widespread use of saddle-path models in economics. 


\section{Appendix: Generating Data that Exhibit Saddle-Path Dynamics}

The simulation experiment dealing with saddle-path dynamics is conducted as follows. First, we find a solution to equation (7) under the saddlepath hypothesis. Second, using the saddle-path solution, we simulate $X_{t}$ of length $T . \mathrm{T}=100$ and $\mathrm{T}=300$ are considered in the exercise. Third, the Johansen test statistic is calculated from the simulated data. The above steps are repeated $N$ times and $N$ is set to 10,000 . The $N$ sample Johansen statistics are then compared with the $5 \%$ critical value to tally the rejection frequency.

We follow the standard procedure to obtain the saddle-path solution to equation (7). Let $B$ be a ( $2 \times 2)$ matrix whose columns contain the eigenvectors of $(A+I)$. Pre-multiplying system (7) by $B^{-1}$, we obtain $Z_{t}=\Lambda Z_{t-1}+U_{t}$ where $Z_{t}=B^{-1} X_{t}, \quad \Lambda=B^{-1}(A+I)$ is a diagonal matrix with the eigenvalues of $(A+I)$ along the diagonal and $U_{t}=B^{-1} V_{t}$. Then, we solve each of the first-order difference equations $z_{i t}=\left(1+\theta_{i}\right) z_{i t-1}+u_{i t} ; \quad i=1,2 \quad$ where $\quad Z_{t}=\left(z_{1 t}, z_{2 t}\right)^{\prime}$ and $U_{t}=\left(u_{1 t}, u_{2 t}\right)^{\prime}$. Under the saddle-path hypothesis, $\theta_{1}<0$ and $\theta_{2}>0$. We solve the first equation backward and the second equation forward. The solutions can be expressed as the sum of two terms:

$$
z_{i t}=z_{i t}^{*}+\left(1+\theta_{i}\right)^{t} c_{i 0}
$$

where

$$
\begin{aligned}
& z_{1 t}^{*}=\sum_{i=0}^{\infty}\left(1+\theta_{1}\right)^{i} u_{1 t-i}, \\
& z_{2 t}^{*}=\sum_{i=0}^{\infty}\left(\frac{1}{1+\theta_{2}}\right)^{i+1} u_{2 t+i+1}
\end{aligned}
$$


and $c_{i 0}=z_{i 0}-z_{i 0}^{*}$. In economics, these two terms are usually labeled the "steady state" and the "bubble." The saddle-path solution is obtained by setting the terminal condition $c_{20}=0$ so that the resulting sequence is not explosive. The original variables of the system are then recovered using $X_{t}=B Z_{t}$.

The steady state $Z_{t}^{*}=\left(z_{1 t}^{*}, z_{2 t}^{*}\right)^{\prime}$ is approximated by the sum of a finite number of elements. We first generate the series $U_{t}$ of length $3 T$ using a normal random number generator. The first $T$ simulated numbers are used to generate $z_{11}^{*}$, the first $T+1$ simulated numbers are used to generate $z_{12}^{*}, \ldots$, and so on. The last $\mathrm{T}$ simulated numbers are used to generate $z_{2 T}^{*}$, the last $T+1$ simulated numbers are used to generate $z_{2 T-1}^{*}, \ldots$, and so on. In addition, the initial condition $c_{10}$ is required to calculate the solution. In the experiment, the initial condition $c_{10}$ is drawn from a normal distribution with zero mean and variance $\sigma_{0}^{2}$. The idea of the random choice is to capture the existence of a continuum of equilibria (each indexed by a different initial condition) lying on the unique stable manifold converging to the steady state. 


\section{References}

Azariadis, C., 1993, Intertemporal Macroeconomics, Blackwell Publisher, Oxford.

Bonham, C., 1991, Correct Cointegration Tests of the Long-Run Relationship between Nominal Interest and Inflation, Applied Economics 23, 14871492

Bruno, M. and S. Fischer, 1991, Seigniorage, Operating Rules, and the High Inflation Trap, Quarterly Journal of Economics 105, 353-374.

Cass, D., 1965, Optimum Growth in an Aggregative Model of Capital Accumulation, Review of Economic Studies 32, 233-240.

Cheung, Y.-W. and K.S. Lai ,1993a, Long-Run Purchasing Power Parity During the Recent Float, Journal of International Economics 34, 181-192.

Cheung, Y.-W. and K.S. Lai ,1993b, Finite-Sample Sizes of Johansen's Likelihood Ratio Tests for Cointegration, Oxford Bulletin of Economics and Statistics 55, 313-328.

Cheung, Y.-W. and K.S. Lai, 2000, On the Purchasing Power Parity Puzzle, Journal of International Economics 52, 321-330.

Cheung, Y.-W., S. Lai and M. Bergman, 2004, Dissecting the PPP Puzzle: The Unconventional Roles of Nominal Exchange Rate and Price Adjustments, Journal of International Economics (forthcoming).

Clarida, R. and J. Gali, 1994, Sources of Real Exchange Fluctuations: How Important are Nominal Shocks?, Carnegie-Rochester Conference Series on Public Policy 41, 1-56.

Dornbusch, R., 1976, Expectations and Exchange Rate Dynamics, Journal of Political Economy 84, 1161-1176. 
Driskill, R.A., 1981, Exchange Rate Dynamics, An Empirical Analysis, Journal of Political Economy 89, 357-371.

Driskill, R.A. and S.M. Sheffrin, 1981, On the Mark: Comment, American Economic Review 71, 1068-1074.

Edison, H.J. and B.D. Pauls, 1993, A Re-Assessment of the Relationship between Real Exchange Rates and Real Interest Rates : 1974-1990, Journal of Monetary Economics 31, 165-87.

Eichenbaum, M. and C.L. Evans, 1995, Some Empirical Evidence on the Effects of Shocks to Monetary Policy on Exchange Rates, Quarterly Journal of Economics 110, 975-1009.

Engel, C. and J.C. Morley, 2001, The Adjustment of Prices and the Adjustment of the Exchange Rate, manuscript, University of Wisconsin.

Evans, J. and G. Yarrow, 1981, Some Implications of Alternative Expectations Hypotheses in the Monetary Analysis of Hyperinflations, Oxford Economic Papers 33, 61-80.

Faust, J., 1998, The Robustness of Identified VAR Conclusions About Money, Carnegie-Rochester Conference Series on Public Policy 41, 1-56

Faust, J. and J.H. Rogers, 1999, Monetary Policy's Role in Exchange Rate Behavior, International Finance Discussion Paper \#652, Board of Governors of the Federal Reserve System.

Frankel, J., 1979, On the Mark: A Theory of Floating Exchange Rates Based on Real Interest Differentials, American Economic Review 69, 610-622.

Frankel, J. and A. Rose, 1995, Empirical Research on Nominal Exchange Rates, Chapter 33 in G. Grossman and K. Rogoff, eds., Handbook of Internationl Economics Vol. 3, 1689-1729, Elsevier - Amsterdam. 
26

Gonzalo, J., 1994, Five Alternative Methods of Estimating Long-Run Equilibrium Relationships, Journal of Econometrics 60, 203-33.

Johansen, S. and K. Juselius, 1990, Maximum Likelihood Estimation and Inference on Cointegration--With Applications to the Demand for Money, Oxford Bulletin of Economics and Statistics 2, 169-210.

King, R., C. Plosser, J. Stock and M. Watson, 1991, Stochastic Trends and Economic Fluctuations, American Economic Review 81, 819-40.

Kugler, P. and C. Lenz, 1993, Multivariate Cointegration Analysis and the LongRun Validity of PPP, Review of Economics and Statistics 75, 180-184.

Meese, R. and K. Rogoff, 1988, Was it Real? The Exchange Rate-Interest Rate Differential Relation over the Modern Floating-Rate Period, The Journal of Finance 43, 933-948. 
Notes.

${ }^{1}$ Strictly speaking, overshooting implies saddle-path but the opposite is not true.

${ }^{2}$ Notice that if equation (7) is written as $X_{t+1}=\mu+\Pi X_{t}+V_{t+1}$, where $\Pi=A+I$, then the roots of $\Pi$, say $\lambda_{1}$ and $\lambda_{2}$, are related to the roots of $A$ according to $\lambda_{i}=1+\theta_{i}, \mathrm{i}=1,2$. Therefore, a unit root of $\Pi$ is equivalent to a zero root of $A$.

${ }^{3}$ King et al. (1991) show in a neoclassical growth framework that (the logs of) output, consumption and investment are cointegrated when thechnology shocks follow an I(1) process, whereas certain ratios characterizing the balanced-growth path (for instance, the consumption-output and the investment-output great ratios) exhibit saddle-path dynamics. 


\section{CESifo Working Paper Series}

(for full list see www.cesifo.de)

1061 Helmuth Cremer and Pierre Pestieau, Wealth Transfer Taxation: A Survey, October 2003

1062 Henning Bohn, Will Social Security and Medicare Remain Viable as the U.S. Population is Aging? An Update, October 2003

1063 James M. Malcomson, Health Service Gatekeepers, October 2003

1064 Jakob von Weizsäcker, The Hayek Pension: An efficient minimum pension to complement the welfare state, October 2003

1065 Joerg Baten, Creating Firms for a New Century: Determinants of Firm Creation around 1900, October 2003

1066 Christian Keuschnigg, Public Policy and Venture Capital Backed Innovation, October 2003

1067 Thomas von Ungern-Sternberg, State Intervention on the Market for Natural Damage Insurance in Europe, October 2003

1068 Mark V. Pauly, Time, Risk, Precommitment, and Adverse Selection in Competitive Insurance Markets, October 2003

1069 Wolfgang Ochel, Decentralising Wage Bargaining in Germany - A Way to Increase Employment?, November 2003

1070 Jay Pil Choi, Patent Pools and Cross-Licensing in the Shadow of Patent Litigation, November 2003

1071 Martin Peitz and Patrick Waelbroeck, Piracy of Digital Products: A Critical Review of the Economics Literature, November 2003

1072 George Economides, Jim Malley, Apostolis Philippopoulos, and Ulrich Woitek, Electoral Uncertainty, Fiscal Policies \& Growth: Theory and Evidence from Germany, the UK and the US, November 2003

1073 Robert S. Chirinko and Julie Ann Elston, Finance, Control, and Profitability: The Influence of German Banks, November 2003

1074 Wolfgang Eggert and Martin Kolmar, The Taxation of Financial Capital under Asymmetric Information and the Tax-Competition Paradox, November 2003

1075 Amihai Glazer, Vesa Kanniainen, and Panu Poutvaara, Income Taxes, Property Values, and Migration, November 2003 
1076 Jonas Agell, Why are Small Firms Different? Managers’ Views, November 2003

1077 Rafael Lalive, Social Interactions in Unemployment, November 2003

1078 Jean Pisani-Ferry, The Surprising French Employment Performance: What Lessons?, November 2003

1079 Josef Falkinger, Attention, Economies, November 2003

1080 Andreas Haufler and Michael Pflüger, Market Structure and the Taxation of International Trade, November 2003

1081 Jonas Agell and Helge Bennmarker, Endogenous Wage Rigidity, November 2003

1082 Fwu-Ranq Chang, On the Elasticities of Harvesting Rules, November 2003

1083 Lars P. Feld and Gebhard Kirchgässner, The Role of Direct Democracy in the European Union, November 2003

1084 Helge Berger, Jakob de Haan and Robert Inklaar, Restructuring the ECB, November 2003

1085 Lorenzo Forni and Raffaela Giordano, Employment in the Public Sector, November 2003

1086 Ann-Sofie Kolm and Birthe Larsen, Wages, Unemployment, and the Underground Economy, November 2003

1087 Lars P. Feld, Gebhard Kirchgässner, and Christoph A. Schaltegger, Decentralized Taxation and the Size of Government: Evidence from Swiss State and Local Governments, November 2003

1088 Arno Riedl and Frans van Winden, Input Versus Output Taxation in an Experimental International Economy, November 2003

1089 Nikolas Müller-Plantenberg, Japan’s Imbalance of Payments, November 2003

1090 Jan K. Brueckner, Transport Subsidies, System Choice, and Urban Sprawl, November 2003

1091 Herwig Immervoll and Cathal O'Donoghue, Employment Transitions in 13 European Countries. Levels, Distributions and Determining Factors of Net Replacement Rates, November 2003

1092 Nabil I. Al-Najjar, Luca Anderlini \& Leonardo Felli, Undescribable Events, November 2003

1093 Jakob de Haan, Helge Berger and David-Jan Jansen, The End of the Stability and Growth Pact?, December 2003 
1094 Christian Keuschnigg and Soren Bo Nielsen, Taxes and Venture Capital Support, December 2003

1095 Josse Delfgaauw and Robert Dur, From Public Monopsony to Competitive Market. More Efficiency but Higher Prices, December 2003

1096 Clemens Fuest and Thomas Hemmelgarn, Corporate Tax Policy, Foreign Firm Ownership and Thin Capitalization, December 2003

1097 Laszlo Goerke, Tax Progressivity and Tax Evasion, December 2003

1098 Luis H. B. Braido, Insurance and Incentives in Sharecropping, December 2003

1099 Josse Delfgaauw and Robert Dur, Signaling and Screening of Workers' Motivation, December 2003

1100 Ilko Naaborg,, Bert Scholtens, Jakob de Haan, Hanneke Bol and Ralph de Haas, How Important are Foreign Banks in the Financial Development of European Transition Countries?, December 2003

1101 Lawrence M. Kahn, Sports League Expansion and Economic Efficiency: Monopoly Can Enhance Consumer Welfare, December 2003

1102 Laszlo Goerke and Wolfgang Eggert, Fiscal Policy, Economic Integration and Unemployment, December 2003

1103 Nzinga Broussard, Ralph Chami and Gregory D. Hess, (Why) Do Self-Employed Parents Have More Children?, December 2003

1104 Christian Schultz, Information, Polarization and Delegation in Democracy, December 2003

1105 Daniel Haile, Abdolkarim Sadrieh and Harrie A. A. Verbon, Self-Serving Dictators and Economic Growth, December 2003

1106 Panu Poutvaara and Tuomas Takalo, Candidate Quality, December 2003

1107 Peter Friedrich, Joanna Gwiazda and Chang Woon Nam, Development of Local Public Finance in Europe, December 2003

1108 Silke Uebelmesser, Harmonisation of Old-Age Security Within the European Union, December 2003

1109 Stephen Nickell, Employment and Taxes, December 2003

1110 Stephan Sauer and Jan-Egbert Sturm, Using Taylor Rules to Understand ECB Monetary Policy, December 2003

1111 Sascha O. Becker and Mathias Hoffmann, Intra-and International Risk-Sharing in the Short Run and the Long Run, December 2003 
1112 George W. Evans and Seppo Honkapohja, The E-Correspondence Principle, January 2004

1113 Volker Nitsch, Have a Break, Have a ... National Currency: When Do Monetary Unions Fall Apart?, January 2004

1114 Panu Poutvaara, Educating Europe, January 2004

1115 Torsten Persson, Gerard Roland, and Guido Tabellini, How Do Electoral Rules Shape Party Structures, Government Coalitions, and Economic Policies? January 2004

1116 Florian Baumann, Volker Meier, and Martin Werding, Transferable Ageing Provisions in Individual Health Insurance Contracts, January 2004

1117 Gianmarco I.P. Ottaviano and Giovanni Peri, The Economic Value of Cultural Diversity: Evidence from US Cities, January 2004

1118 Thorvaldur Gylfason, Monetary and Fiscal Management, Finance, and Growth, January 2004

1119 Hans Degryse and Steven Ongena, The Impact of Competition on Bank Orientation and Specialization, January 2004

1120 Piotr Wdowinski, Determinants of Country Beta Risk in Poland, January 2004

1121 Margarita Katsimi and Thomas Moutos, Inequality and Redistribution via the Public Provision of Private Goods, January 2004

1122 Martin Peitz and Patrick Waelbroeck, The Effect of Internet Piracy on CD Sales: CrossSection Evidence, January 2004

1123 Ansgar Belke and Friedrich Schneider, Privatization in Austria: Some Theoretical Reasons and First Results About the Privatization Proceeds, January 2004

1124 Chang Woon Nam and Doina Maria Radulescu, Does Debt Maturity Matter for Investment Decisions?, February 2004

1125 Tomer Blumkin and Efraim Sadka, Minimum Wage with Optimal Income Taxation, February 2004

1126 David Parker, The UK's Privatisation Experiment: The Passage of Time Permits a Sober Assessment, February 2004

1127 Henrik Christoffersen and Martin Paldam, Privatization in Denmark, 1980-2002, February 2004

1128 Gregory S. Amacher, Erkki Koskela and Markku Ollikainen, Deforestation, Production Intensity and Land Use under Insecure Property Rights, February 2004

1129 Yin-Wong Cheung, Javier Gardeazabal, and Jesús Vázquez, Exchange Rate Dynamics: Where is the Saddle Path?, February 2004 